\title{
Observations of Energy Fluxes and Evapotranspiration over Terrestrial Complex Land Covers in the Tropical Monsoon Environment
}

\author{
Motomu TODA \\ Japan Science and Technology Corporation, Domestic Research Fellow, Saitama, Japan \\ Kenlo NISHIDA \\ Institute of Agricultural and Forest Engineering, University of Tsukuba, Ibaraki, Japan \\ Nobuhito OHTE, Makoto TANI \\ Division of Environmental Science and Technology, Graduate School of Agriculture, Kyoto University, Kyoto, \\ Japan \\ and \\ Katumi MUSIAKE \\ Institute of Industrial Science, University of Tokyo, Tokyo, Japan
}

(Manuscript received 10 September 2000, in revised form 15 February 2002)

\begin{abstract}
The surface energy flux balance and total evapotranspiration were estimated using the eddy correlation, and bandpass covariance technique over a tropical monsoon environment within the framework of GEWEX (Global Energy and Water cycle Experiment) Asian Monsoon Experiment (GAME). The aim of this present study is to obtain information on the seasonal variation of heat and water vapor exchanges between the atmosphere and terrestrial land cover (complex area) in tropical monsoon environment.

The result indicated the daily integrated values of net radiation, sensible heat, latent heat and ground heat flux during the observation period from July 1998 to February 1999 were $10.76 \mathrm{MJ} \mathrm{m}^{-2}$, $2.32 \mathrm{MJ} \mathrm{m}^{-2}, 5.18 \mathrm{MJ} \mathrm{m}^{-2}$ and $0.03 \mathrm{MJ} \mathrm{m}^{-2}$, respectively. Sensible and latent heat fluxes were the dominant energy partitioning components throughout the year. The seasonal difference in surface fluxes between wet and dry seasons was seen, and the latent heat flux was dominant in the monsoon, corresponding with the increase of specific humidity after frequent precipitation. Whereas the sensible heat flux increased as the surface temperature increased in the absence of rainfall during the dry season. However, the closure of energy balance remained unresolved as with the foregoing experimental studies. The estimated amount to evapotranspiration was $526 \mathrm{~mm}$ versus $641 \mathrm{~mm}$ of actual precipitation, and accounted for about $80 \%$ of the precipitation during this period.
\end{abstract}

Corresponding author and present affiliation: Motomu Toda, Forestry and Forest Products Research Institute, 1, Matsunosato, Kukizaki-machi, Inashiki 305-8687, Japan.

E-mail: todam@ffpri.affrc.go.jp

(C) 2002, Meteorological Society of Japan

\section{Introduction}

It has been recognized that the heat and water vapour exchanges resulting from the interaction between the land and atmosphere in the tropical monsoon climate environment play 
a major role not only in causing local convection, but also in acting as the source of the overall climatic condition, such as the onset or decline of the monsoon and the seasonal and inter-annual variations of ENSO (ElNiño Southern Oscillation). It has been suggested that the recent drastic conversion of land uses through wider deforestation in the tropics has brought about tremendous changes in surface energy balances. For instance, Kondoh (1995) used several global datasets provided by NOAA/ EPA (National Oceanic \& Atmospheric Administration/Environmental Protection Agency), to explain how changes in land utilization in an Asian region dramatically changed evapotranspiration. However, we still do not get enough knowledge of the surface-atmospheric interaction processes under such conditions.

The continuous observation of turbulent heat and water vapor fluxes in association with meteorological and hydrological variables has been carried out over terrestrial complex land cover in tropical regions as part of the fundamental framework of the GAME since May 1998. The significant aims of the present study are to enhance our understanding of the energy and water vapor exchange between a vegetative surface and the atmosphere, and to quantitatively evaluate the total amount of energy balance, and evapotranspiration, by means of micro-meteorological measurements during the observation period.

In order to evaluate the long-term energy balance and evapotranspiration, during the past decade, a number of the experimental studies have been carried out on various terrestrial land surfaces such as forests, grasslands, and paddy fields throughout the world (e.g., Black et al. 1996; Greco et al. 1996; Kabat et al. 1997; Rosset et al. 1997; Toda et al. 2000a). However, observations on the surface fluxes have rarely been made on the tropical monsoon environment in Asia, although many have been conducted in tropical rainforests since it is recognized that the tropical rainforest is the most powerful evaporative source, with continual rainfall throughout a year. However, knowledge of surface fluxes over the tropical monsoon forest, with the extreme dry and wet periods in a year, is useful for evaluating the global water budget including the tropical terrestrialatmospheric interaction.
One possible approach for the long-term evaluation of surface fluxes is the eddy correlation method, which is one of the micrometeorological methods. In this approach, use is made of weatherproof sonic anemometerthermometer, since it can directly measure most sizes of turbulence in which most of the energies are contained in the air at a fast rate of $10 \mathrm{~Hz}$, and fluxes of momentum and sensible heat can be calculated. A combination of the eddy-correlation, and the bandpass covariance method also allows the calculation of latent heat flux in terms of long-term measurement owing to instrumentation problems. Bandpass covariance method have been incorporated into the third-generation Portable Automated Mesonet (PAM III), developed by Horst and Oncley (1995). The present paper describes the seasonal variations of the energy balance, using these micro-meteorological methods, and are investigated with over a one and half year period (June 1998 to October 1999), and the total amount of evapotranspiration over complex land covers is estimated for the period in which the observation data were obtained, including the wet and dry season (June 1998 to February 1999).

\section{Description of experiment}

\subsection{Characteristics of the site}

A surface flux station $\left(99^{\circ} 25^{\prime \prime} 792 \mathrm{E}\right.$, $16^{\circ} 56^{\prime \prime} 392 \mathrm{~N}$ ) $121 \mathrm{~m}$ above sea level was established in the Chao Phraya river basin about 60$\mathrm{km}$ east from Tak province, Thailand in 1998. The topography around the experimental field is essentially flat and with a very gentle undulation except for 100-m high hill approximately $1.5 \mathrm{~km}$ east of the observation tower. Figure 1 shows that the surrounding area has several types of land cover, which consist of mainly evergreen and deciduous forests with their height ranging from $5 \mathrm{~m}$ to $20 \mathrm{~m}$ tall, as well as paddy fields, grasslands, farmlands, grazing, water reservoirs and villages within a radius of about $20 \mathrm{~km}$ of the observation tower. However, the complexity of land conditions would be considered statistically homogeneous on a regional scale. Figure 2 (a) to (c) indicate the seasonal variation of land cover around the observation tower. Photographs were taken at the top of the 120-m high observation tower on (a) August 1998, (b) November 1998, and (c) March 1999, 


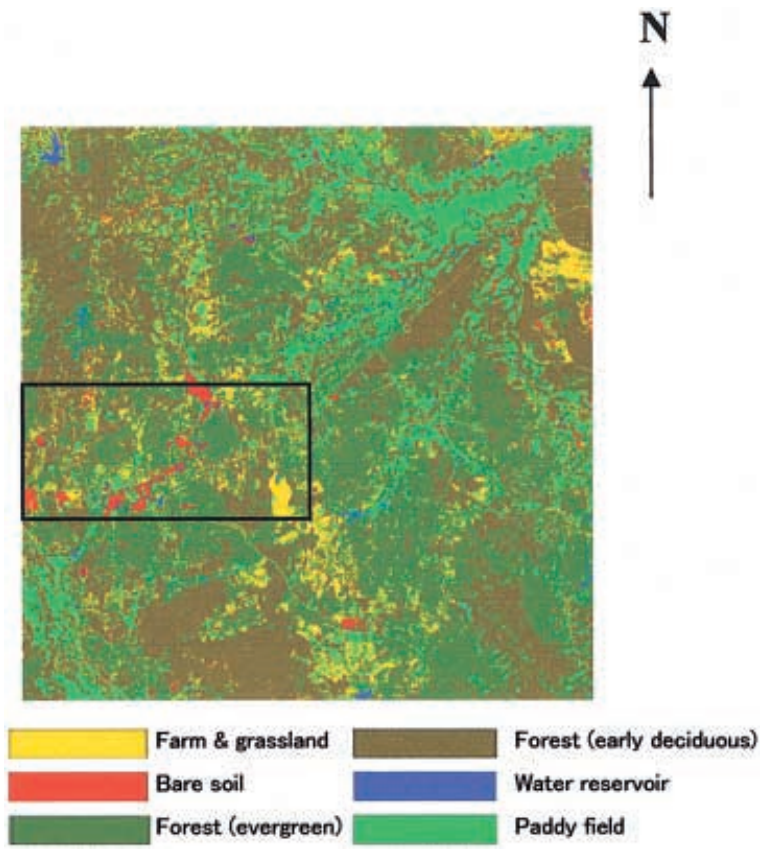

Fig. 1. Map of land cover around the observation tower within about 20 by 20 square kilometers. Six types of land cover are classified, with the observation tower considered as the center of the corresponding area. The enclosed area with tetragon corresponds with that used in Figures 2(a) to (c). corresponded with the area enclosed with tetragon in Fig. 1. As shown in Fig. 2(a) and (b), there were seen the forests, grassland and paddy which grew up during wet season. In contrast, grassland and paddy were not seen clearly during the dry season, but the tree stands were scattered around the tower.

Table 1 shows the ratio of land use classification in every direction. A set of the eddy turbulence flux instruments was mounted toward South to East (S-E), and South to West (S-W) direction. In this region, more than $70 \%$ of the land is occupied by the evergreen and deciduous forest, and paddy field.

Figure 3 shows the seasonal variation in the Normalized Differential Vegetation Index (NDVI), and brightness surface temperature $T_{B}$ over the observation site, estimated using LANDSAT-TM data for the $20 \times 20$ square kilometer regions during the observation period from June 1998, to October 1999. The value of NDVI was calculated from brightness of the two wavelength bands using the following equation.

$$
N D V I=\frac{B_{s}-B_{l}}{B_{s}+B_{l}}
$$

where $B_{s}$ and $B_{l}$ mean the brightness of the (a)

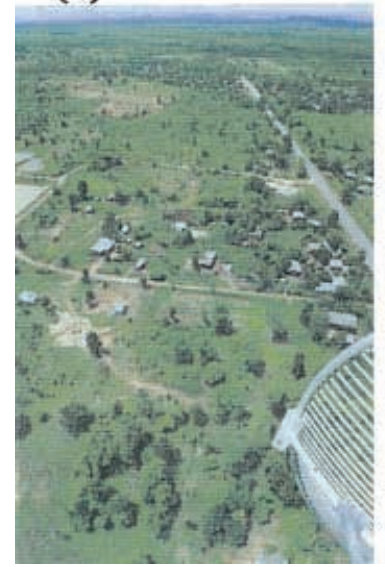

(b)

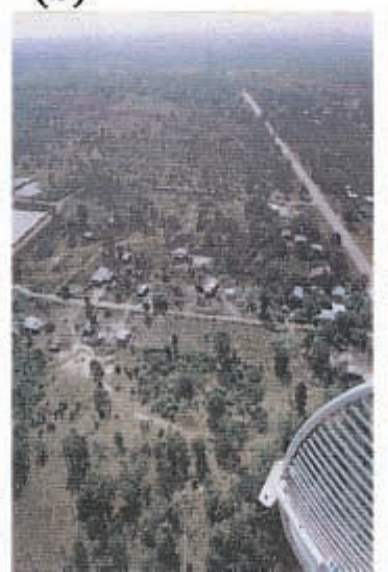

(c)

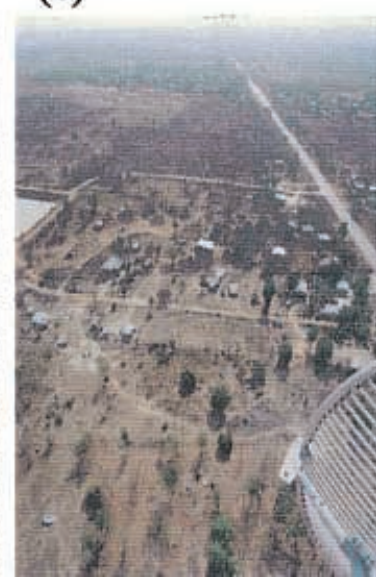

Fig. 2. Seasonal variation of land cover around the observation tower. Photographs were taken at the top of the 120-m high observation tower on (a) August 1998, (b) November 1998, and (c) March 1999. The direction indicates South-West from the tower. 
Table 1. Percentage of individual land cover around the observation tower. The area considered in Table 1 is the same as in Fig. 1.

\begin{tabular}{|c|cccc}
\hline Direction & $\mathrm{N}-\mathrm{W}$ & $\mathrm{S}-\mathrm{W}$ & $\mathrm{N}-\mathrm{E}$ & $\mathrm{S}-\mathrm{E}$ \\
Land use & $\%$ & $\%$ & $\%$ & $\%$ \\
\hline Farmland \& grassland & 9.3 & 7.5 & 7.7 & 8.7 \\
Bare soil & 1.0 & 1.0 & 1.7 & 0.3 \\
Evergreen forest & 22.3 & 18.0 & 31.3 & 43.7 \\
Deciduous forest & 58.8 & 50.0 & 51.2 & 37.4 \\
Water reservoir & 0.8 & 0.3 & 0.1 & 0.4 \\
Paddy field & 7.8 & 25.3 & 8.0 & 9.5 \\
\hline
\end{tabular}

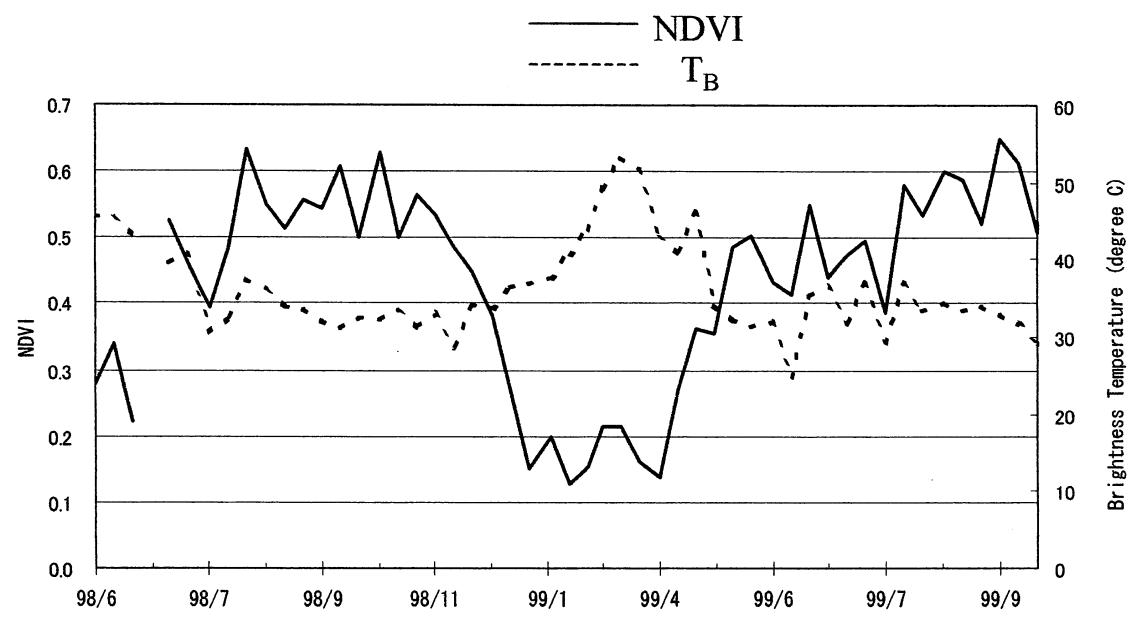

Month (1998 - 1999)

Fig. 3. Seasonal variation of NDVI and brightness surface temperature $T_{B}$ during June 1998 to Semptember 1999.

wavelength bands, and $B_{s}$ reflecting the chlorophyll densities in relation with the plant activities. In the present study, $B_{s}$ is selected from those with the densities ranging from $0.63 \mathrm{~nm}$, to $0.69 \mathrm{~nm} . B_{l}$ is determined in the near infrared domain in the range from $0.76 \mathrm{~nm}$, to $0.90 \mathrm{~nm}$. Nemani and Running (1989) derived a linear relationship of $L A I$ to NDVI using LANDSAT-TM data from several types of land covers. For instance, the empirical equation for broadleaf forest was specified as follows,

$$
L A I=(N D V I / 0.26)^{2} .
$$

The result of Fig. 2 shows that there was the seasonal difference in NDVI in the ranging from $N D V I=0.14$ to 0.63 , and it supports the large seasonal variations of $L A I$. The seasonal behavior of $L A I$ changes drastically in association with the coming/going of the monsoon with the increase/decrease of precipitation. The $L A I$ calculated using equation (2) ranges from 0.28 $\mathrm{m}^{2} \mathrm{~m}^{-2}$ to $5.8 \mathrm{~m}^{2} \mathrm{~m}^{-2}$ throughout a year, assuming that the observation is conducted over the broadleaf forest.

\subsection{Surface fluxes measurement}

Eddy correlation technique was applied to derive the momentum, and sensible heat fluxes, using a three-dimensional sonic anemometerthermometer (model:R3A, GILL), mounted $60 \mathrm{~m}$ high. The turbulence variables for the 
3 wind components, and virtual temperature were obtained at a sampling rate as fast as $10 \mathrm{~Hz}$, and the momentum flux $(\tau)$, and virtual sensible heat flux $\left(H_{s}\right)$, were calculated as follows.

$$
\begin{aligned}
& \tau=-\rho \overline{u^{\prime} w^{\prime}}, \\
& H_{s}=c_{p} \rho \overline{w^{\prime} t^{\prime}},
\end{aligned}
$$

where the overbar (-) and prime $\left({ }^{\prime}\right)$ respectively mean the time averaging and deviation from the average. $u, w$ and $t$ represent the horizontal and vertical velocity components, and sonic virtual temperature fluctuations. Each covariance was averaged at an interval of 10 minutes. $\rho$ is the air density, $c_{p}$ is the specific heat of the air at constant pressure. Also, the sensible heat flux $H$ is evaluated after eliminating the effect of water vapor obtained by using equation (5) below,

$$
\begin{aligned}
H & =H_{s}-0.06 L E \\
& =c_{p} \rho \overline{w^{\prime} t^{\prime}}-0.06 L \rho \overline{w^{\prime} q^{\prime}} .
\end{aligned}
$$

Where $L$ is the latent heat of evaporation, $E$ the evaporation rate, and $q^{\prime}$ is the specific humidity fluctuation.

The selection of data must be considered when estimating the seasonal variation of surface fluxes. In the turbulent analysis of this study, acceptable data were selected in the absence of rainfall. In fact, additional data selection could have been made to assess the impact of the tower structure, and sonic anemometer itself, on wind distortion. Seginer et al. (1976) discussed the influence of eddies shed by the rods on the turbulence observed inside a confined canopy, based on wind tunnel experiments to simulate an unconfined plant canopy. They found that the influence was clearly seen, but was small.

A simple test was conducted to evaluate the effect of the tower, and sonic anemometerthermometer on the turbulent flow with the same method as that of Seginer et al. (1976) using Strouhal number $S t$ given by,

$$
S t=n D / U \text {, }
$$

where $n$ is the frequency, and $D$ the diameter of the tower, assuming the tower to be a cylindrical structure. The value of $S t$ is constant $(S t=0.21)$ when the Reynolds number $R e$ is greater than 1000 (Seginer et al. 1976). $U$ is the averaged wind speed. From equation (6), the frequency $n$ of eddy shedding by the tower, and sonic anemometer-thermometer in our site, should be around $n=0.17 \mathrm{~Hz}$.

Figure 4 (a) represents the daytime power spectra for longitudinal $u$, lateral $v$, vertical $w$ wind, and temperature $t$ fluctuations measured using the sonic anemometer as a function of $n$. This figure also includes the dotted line for the frequency $n=0.17$, related with the Strouhal number on the present data. Data in the daytime was selected with an averaged wind speed of $6 \mathrm{~ms}^{-1}$ from behind the observation tower, and the sonic anemometer-thermometer on 20 February 1999. At the high-frequency more than $n=0.01 \mathrm{~Hz}$, all the curves fell off approximately as the $-5 / 3$ power law in the inertial sub-range of frequencies. As shown in Fig. 4 (a), the obvious spikes related with the wind distortion were not seen around Strouhal frequency $n=0.17 \mathrm{~Hz}$ for each spectrum, and this indicates that eddies around $n=0.17 \mathrm{~Hz}$ were not influenced by the tower or sensor itself. Figure 4(b) represents that the normalized power spectra estimates for the ensemble of 49 runs with the same components as shown in Fig. 4 (a) are plotted to the nondimensional frequency $f=n\left(z_{m}-d\right) / U$, where $z_{m}$ is the measurement height above the zero plane displacement $d$. The value of $d$ was determined as $d=16 \mathrm{~m}$ using the variance method (Toda and Sugita 2002). The integral over the plotted frequency range of each spectrum gives unity. The peak frequency was obtained around $f=0.02$ for $u, v$ and $t$, and $f=0.04$ for $w$. The result indicates that more than $95 \%$ of the total observed energy was contained in the frequency ranges, until the nondimensional frequency $f=2.38$ related with the Strouhal number. Even if the peak frequency in the wake spectrum was seen around the frequency related with Strouhal number, the influences of wind distortion on the surface fluxes should be small. Hence, all of the data obtained during the observation period can be used for the long-term surface flux estimates, but in the absence of rainfall.

\subsection{Data acquisition system}

In the case of long-term flux observation, the data acquisition system PAM III is used as described in Chapter 1, and calculates aver- 

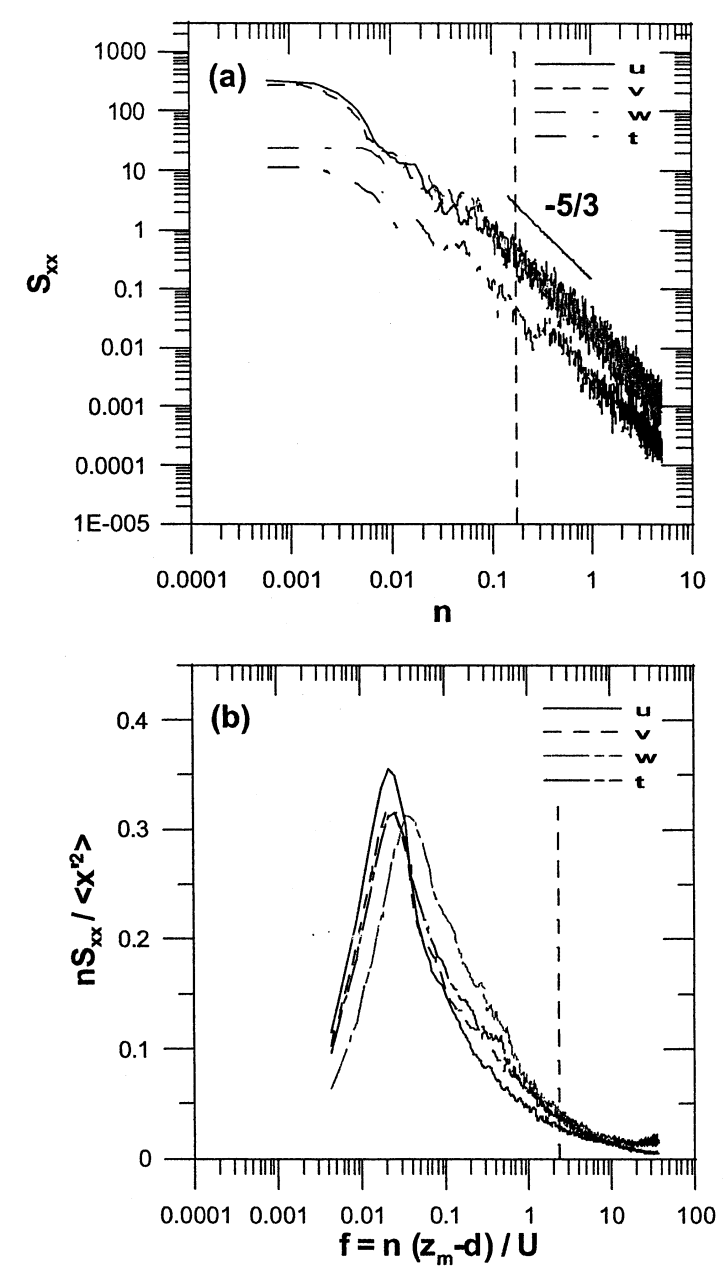

Fig. 4. (a) Daytime power spectra for longitudinal $u$, lateral $v$, vertical $w$ wind and temperature $t$ fluctuations on 20 February 1999 (12:00:00-12:30:00 Thailand Standard Time). The dotted line for the frequency $n=0.17 \mathrm{~Hz}$ related with Strouhal number is included in the figure. (b) Normalized power spectra for the same components as shown in Figure 4 (a) but for the ensemble of forty-nine, 30 minute turbulent data during 20 February (DOY 51) to 3 March (DOY 629) 1999.

age, variance, and covariance between vertical wind fluctuation for every flux component as 10 minutes mean value. PAM/Environmental Variable Extractor EVE includes the current configuration to calculate the momentum, and sensible heat fluxes with eddy correlation, and the latent heat flux with bandpass covariance technique.

The scalar flux is generally estimated by the integration of all frequency components that contribute to it. The commercial fast-response sensor, like the open-path gas analyzer, can directly observe scalar fluxes such as water vapour and carbon dioxide up to high frequency components. However, it is of limited use in long-term estimation of the scalar fluxes because of its unstable drift behavior and imperfect weatherproofness (Watanabe et al. 2000). In contrast, the slow-response sensor, like the capacitive relative humidity sensor, has the advantage of being stable and weatherproof but it is less capable of detecting high frequency components than the fast-response. Hence, in the case that long-term observations are being made at remote sites where it is difficult to regularly maintain measurement sensors, bandpass technique is available for taking continuous measurements of the scalar flux. Thus, the latent heat flux is estimated by means of capacitive relative humidity and platinumresistance temperature transducers (model 50Y, Vaisala) as slow response sensors mounted at the same height as the sonic anemometerthermometer.

Bandpass technique is based on the assumption of cospectral similarity in the atmospheric surface layer (e.g., Hicks and McMillen 1988). On the assumption that the ratio of the covariance for $w^{\prime}$, and specific humidity fluctuation $q^{\prime}\left(w^{\prime} q^{\prime}\right)$ to $w^{\prime} t^{\prime}$, is the same at high frequencies as it is at lower frequencies, the high frequency components of the latent flux, which can not be measured directly, is calculated as follows;

$$
\frac{\left(\overline{w^{\prime} t^{\prime}}\right)_{b p}}{\left(\overline{w^{\prime} q^{\prime}}\right)_{b p}}=\frac{\left(\overline{w^{\prime} t^{\prime}}\right)_{h p}}{\left(\overline{w^{\prime} q^{\prime}}\right)_{h p}}=\beta,
$$

where $\beta$ represents the bandpass ratio. The subscripts ' $b p$ ' and ' $h p$ ' mean the bandpass and high-pass frequency region, respectively. The bandpass frequency region is defined as ()$_{b p}$, in the range of $f_{L} \leq f \leq f_{H}$. The lower limit $f_{L}$ of the bandpass region is dependent on the sampled time at 10-minute intervals. In contrast, the upper limit $f_{H}$ of the bandpass region is restricted to $f_{H}<1 / 2 \pi \mu$ with the time constant of relative humidity transducer $\mu$, as specified 
below. Whereas, the high-pass frequency region is represented as ()$_{h p}$ in the range of $f_{H} \leq f \leq$ $f_{H l}$, provided that $f$ is larger than $f_{H}$. Here, $f_{H l}$ is determined by the sampled frequency rate.

With equation (7), the latent heat flux $L E$ can be written by

$$
\begin{aligned}
L E & =L \rho\left[\left(\overline{w^{\prime} q^{\prime}}\right)_{l p}+\left(\overline{w^{\prime} q^{\prime}}\right)_{b p}+\left(\overline{w^{\prime} q^{\prime}}\right)_{h p}\right] \\
& =L \rho\left[\left(\overline{\bar{w}^{\prime} q^{\prime}}\right)_{l p}+\left(\overline{w^{\prime} q^{\prime}}\right)_{b p}+\frac{1}{\beta}\left(\overline{w^{\prime} t^{\prime}}\right)_{h p}\right],
\end{aligned}
$$

where the subscript ' $l p$ ' also denotes the lowpass frequency region in the range of $f<f_{L}$. Thus, the determination of the bandpass ratio $\beta$ is made within PAM III computational algorithm as follows.

The value of $\beta$ can be also identical to the measured cospectra ratio $C_{o w^{\prime} t^{\prime}} / C_{o w^{\prime} q^{\prime}}$ for $w^{\prime} t^{\prime}$ and $w^{\prime} q^{\prime}$ in the bandpass frequency domain. Indeed, the capacitance relative humidity transducer has approximately a first-order response with $\mu$, and then the corrected cospectra $C_{o w^{\prime} q^{\prime}}^{m}$ for $w^{\prime} q^{\prime}$ by means of $\mu$ is as follows,

$$
C_{o w^{\prime} q^{\prime}}^{m}=\frac{C_{o w^{\prime} q^{\prime}}}{1+(2 \pi f \mu)^{2}} .
$$

Hence, substantial relation for the cospectra $R(f) \equiv C_{o w^{\prime} t^{\prime}}^{m} / C_{o w^{\prime} q^{\prime}}^{m}$ with equation (9) is given by

$$
\begin{aligned}
R(f) & =\frac{C_{o w^{\prime} t^{\prime}}^{m}}{C_{o w^{\prime} q^{\prime}}^{m}}=\frac{C_{o w^{\prime} t^{\prime}}}{C_{o w^{\prime} q^{\prime}}}\left[1+(2 \pi f \mu)^{2}\right] \\
& =\beta\left[1+(2 \pi f \mu)^{2}\right]=a+b f^{2} .
\end{aligned}
$$

Thus, $\beta$ can be determined from the intercept of a linear fit of $R(f)$ versus $f^{2}$, and the latent heat flux $L E$ can be estimated with $\beta$ and equation (8).

It should be noted that the final determination should be made of the covariance on 30minute mean $\overline{w^{\prime} q^{\prime}} 30$. The value of $\overline{w^{\prime} q^{\prime}} 30$ can be written as follows:

$$
{\overline{w^{\prime} q^{\prime}}}^{30}={\overline{w^{\prime} q^{\prime}}}_{1}^{30}+{\overline{w^{\prime} q^{\prime}}}_{2}^{30} .
$$

The first term $\left(\overline{w^{\prime} q^{\prime}}{ }_{1}^{30}\right)$ in equation (11) is written as $\overline{w^{\prime} q^{\prime}}{ }_{1}^{30}\left(=\frac{1}{3} \sum_{i=1}^{3}\left(\overline{w_{i}^{\prime} q_{i}^{\prime}} 10\right)\right)$, where $\left({\overline{w_{i}^{\prime} q_{i}^{\prime}}}^{10}\right)$ is the covariance on 10 -minute mean recorded using PAM III. $\left(\overline{w^{\prime} q^{\prime}}{ }_{2}^{30}\right)$ is also the 30minute mean of the covariance for the low frequency component, considering the eddy with time scale longer than 10 minutes. Thus, $\left(\overline{w^{\prime} q^{\prime}}{ }_{2}^{30}\right)$ is given by

$$
\begin{aligned}
{\overline{w^{\prime} q^{\prime}}}_{2}^{30}= & \frac{1}{3} \sum_{i=1}^{3}\left|{\overline{w_{i}}}^{10}{\overline{q_{i}}}^{10}+{\overline{\overline{w_{i}}}}^{10}{q_{i}^{\prime}}^{10}+{\overline{w_{i}^{\prime}{\overline{q_{i}}}^{10}}}^{10}\right| \\
& -\frac{1}{3} \sum_{i=1}^{3}\left({\overline{w_{i}}}^{10}{\overline{q_{i}}}^{10}\right) .
\end{aligned}
$$

\subsection{Auxiliary measuring instruments}

Meteorological components were measured at the $30-\mathrm{m}$ height on the observation tower. Photosynthetic active radiation (PAR), and the net radiation balance were observed using a light quantum sensor (model LI-190SZ, LI$\mathrm{COR}$ ), and a net radiometer (model Q7, REBS), respectively. The upward short wave radiation with pyranometer (model ML-020V, EKO) was also measured at the same height. They were attached to the tip of a 4-m long boom, considering the prevailing wind direction. The surface temperature was measured using infrared radation thermometer (Model 4000. 4G, Everex) at $30 \mathrm{~m}$ height. The air temperature, and the relative humidity, were measured with platinum-resistance temperature transducers and capacitive relative humidity (model 50Y, Vaisala) using ventilated psychrometers (Type S-301, Yoshino), and the wind speed and direction were measured with wind velocity sensors (model CS800-L, Campbell Scientific).

The soil heat flux was estimated by averaging the outputs of the two heat flux plates buried $0.01 \mathrm{~m}$ below the surface near the tower (model MF-81, EKO; model HFT-3.1, REBS) considering the spatial heterogeneity of ground heat in association with the soil moisture.

Volumetric soil moisture content was measured using a time domain reflectmertry (TDR) (model CS615, Campbell Scientific, Inc.) at positions $0.05,0.15,0.25$ and $0.35 \mathrm{~m}$ below the surface, respectively. The soil moisture content was calculated by deriving the empirical expression from the adherent relationship between the values measured by TDR and the volumetric soil moisture content obtained from the oven dry method using the soil sampled at the location where the TDR was buried. In order to determine the representative soil water content around the tower, the outputs of the same type of TDRs buried at the same depth in different places were compared with each other. 
Their differences were within an average range of $20 \%$ due to the heterogeneous distributions of soil pores and moisture conditions. Precipitation was measured using a tipping bucket rain gauge (model TE525, Texas Electrics). The supplementary meteorological and hydrological variables used in the present study were recorded on a compact flash PCMCIA memory card in EVE every 10 minutes. The present analysis was made by 30 -minute averaged data as well as the turbulent flux data.

\section{Results}

\subsection{Seasonal variation for meteorological variables and surface fluxes \\ a. Features of meteorological and soil moisture conditions}

This chapter examines seasonal variations in the energy balance over a period of one and a half years (June 1998 to October 1999).

Figures 5 (a) to (e) show the meteorological variables on a daily basis from 1 June (DOY 152) 1998 to 21 October (DOY 294) 1999. Data were collected from 303 of the 511 days in this period. The maximum values of daily-integrated downward PAR were from 50 to $60 \mathrm{~mol} \mathrm{~m}^{-2}$ day $^{-1}$, which corresponded to 14.9 to 17.9 $\mathrm{MJ} \mathrm{m}{ }^{-2}$ day $^{-1}$ of solar radiation.

The daily aggregated PAR was $28.5 \mathrm{~mol} \mathrm{~m}^{-2}$ day $^{-1}$ (8.5 $\mathrm{MJ} \mathrm{m}^{-2}$ day $^{-1}$ ) on average during the observation period. The averaged value of daily PAR was $28.8 \mathrm{~mol} \mathrm{~m}^{-2}$ day $^{-1}\left(8.6 \mathrm{MJ} \mathrm{m}^{-2}\right.$ day $^{-1}$ ), with data obtained during the rainy season (217 days data was used during DOY 206 to DOY 340 1998, and during 5 April (DOY 95) to 21 October (DOY 294) 1999) and 28.4 $\mathrm{mol} \mathrm{m}^{-2}$ day $^{-1}$ (8.2 $\mathrm{MJ} \mathrm{m}^{-2}$ day $^{-1}$ ) during the dry season (86 days data was used during 4 December (DOY 338) to 31 December (DOY 365) 1998 and during 1 January (DOY 1) to 4 April (DOY 94) 1999), and there were not remarkable differences between them on the seasonal basis, although the seasonal change of PAR on the daily basis was shown in Fig. 5(a).

The averaged value of the ratio of the upward in Fig. 5(b), and downward short wave radiation, surface albedo was approximately 0.2 with data obtained during observation period, reflecting on the vegetative condition, and surface wetness.

The seasonal variation of the surface temperature $\left(T_{s}\right)$ was shown in Fig. 5 (c). The value
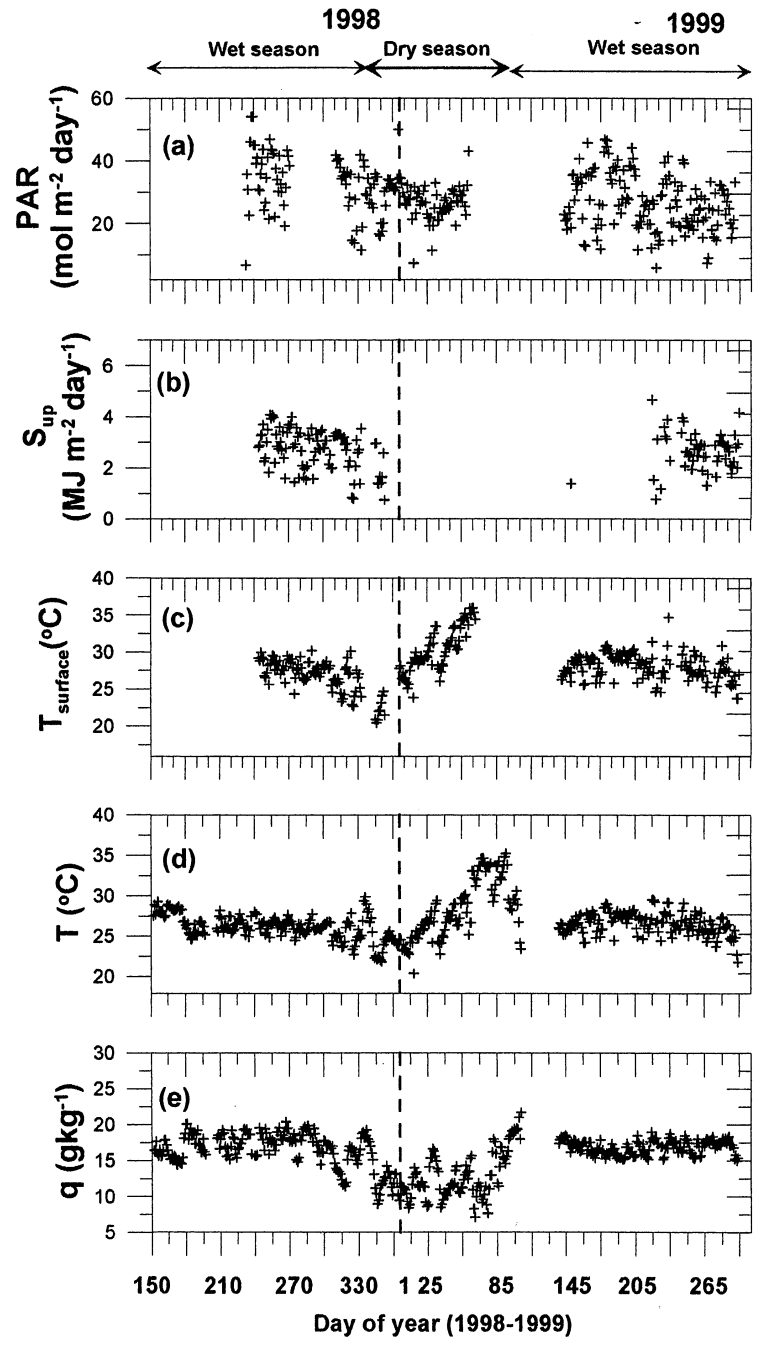

Fig. 5. Seasonal variations of meteorological and hydrological variables (from (DOY 152) 1998 to (DOY 294) 1999). (a) Daily integrated photosynthesis active radiation (PAR), (b) Daily integrated upward solar radiation $\left(S_{u p}\right)$, (c) daily mean surface temperature $\left(T_{\text {surface }}\right),(\mathrm{d})$ daily mean air temperature $(T)$, and (e) daily mean specific humidity $(q)$.

of $T_{s}$ decreased gradually during the rainy to the dry season, and fell about $20^{\circ} \mathrm{C}$ at daily minimum in December 1998. $T_{s}$ increased gradually from December 1998, until April 1999 and was $36^{\circ} \mathrm{C}$ at daily maximum during April before the onset of monsoon in 1999 started.

As shown in Fig. 5(d), the daily average air temperature was $27.1^{\circ} \mathrm{C}$ during the entire year, and a small variation in the seasonal behavior 

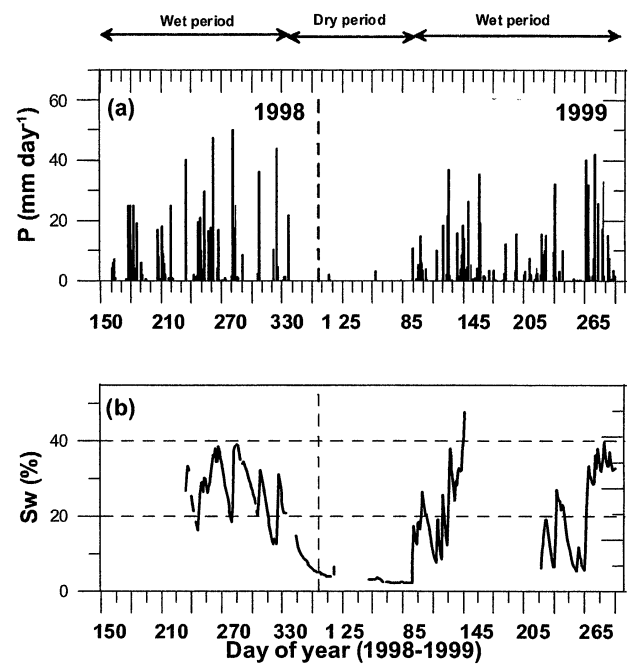

Fig. 6. Same as Figure 5 but (a) for daily accumulated precipitation $(P)$, and $(b)$ daily mean volumetric soil moisture $\left(S_{w}\right) 0.05 \mathrm{~m}$ below the surface.

was seen ranging from $24.8^{\circ} \mathrm{C}$ (December 1998) to $32.0^{\circ} \mathrm{C}$ (March 1999). The frequent precipitation in April 1999 caused abrupt reduction in air temperature up to the same level as obtained during the wet season in 1998. The daily average specific humidity increased from $7.2 \mathrm{~g} \mathrm{~kg}^{-1}$ on 7 March (DOY 66) 1999, to $21.6 \mathrm{~g} \mathrm{~kg}^{-1}$ on 16 April (DOY 106) 1999.

Figure 6 (a) shows drastic change in precipitation. Matsumoto (1997) determines the mean onset, and withdrawal of summer rainy season over the Indochina Peninsula using 5-day mean precipitation data. Miyazaki et al. (1999) indicates that the on/off-set in the monsoon could be generally predicted from the seasonal variation of the specific humidity in the atmosphere. In the present study, data were used of specific humidity and precipitation in order to predict the on/off-set in the monsoon. The meteorological database obtained from Thailand Meteorological Department, indicates that drastic increases in precipitation already began in the middle of May 1998, and while they did in April 1999 (from (DOY 95)). The total amount of precipitation during the observation period was $724 \mathrm{~mm}$ in 1998, and $744 \mathrm{~mm}$ in 1999, respectively. There was not much precipitation during the dry period, from the beginning of December 1998 (from 4 December (DOY 338)) to
April 1999 (until 4 April (DOY 94)). Figure 6 (b) indicates the seasonal variations of volumetric soil moisture content at $0.05 \mathrm{~m}$ below the surface. It indicated that the remarkable seasonal variations of soil moisture almost corresponded to the changes in precipitation, but there existed the time-lag until the sufficient soil moisture has been charged in the soil. During the rainy season, the soil moisture changed in a range from approximately $20 \%$ to $48 \%$, whereas soil moisture fell to $2 \%$ in February (from 9 February (DOY 40)) 1999, when the dry period began.

\section{b. Surface fluxes}

Figure 7 shows the seasonal variations in daily averaged surface energy flux components. The maximum value of net radiation reached $18.33 \mathrm{MJ} \mathrm{m}^{-2}$ day $^{-1}$ in June 1998 . It is possible to speculate that the daily net radiation might have remained high during in July, provided the measurements were successful. After 10 September (DOY 253) 1998 the daily net radiation decreased gradually down to $8.12 \mathrm{MJ} \mathrm{m}^{-2}$ day $^{-1}$ during January 1999, since both of the upward solar radiation $\left(S_{u p}\right)$, and upward long wave radiation $\left(L_{u p}\right)$, which was derived using $T_{\text {surface }}$ as indicated in Fig. 5 (c), by the following from,

$$
L_{u p}=\sigma T_{\text {surface }}^{4},
$$

where $\sigma$ is the Stefan-Boltzmann constant $\left(=5.67 \times 10^{-8} \mathrm{~W} \mathrm{~m}^{-2} \mathrm{~K}^{-4}\right)$, increased in accordance with the seasonal changes in surface wetness, surface conditions (Tanaka et al. 2001), and surface temperature, respectively. The daily net radiation increased again due to the increase of solar elevation from the end of January 1999. The magnitude of $G$ on a daily basis was $3 \mathrm{MJ} \mathrm{m}^{-2}$ day $^{-1}$, to the positive or negative side throughout the entire period. Thus, most of the net radiation distributed to the sensible heat, and latent heat flux components.

During the middle of June 1998, the sensible heat reached nearly $10 \mathrm{MJ} \mathrm{m}{ }^{-2}$ day $^{-1}$, and it indicated 3 times greater than that of latent heat flux during the corresponding period. As shown in Fig. 6 (a), the increase of precipitation in the corresponding season already started. The partitions of the sensible and latent heat fluxes to net radiation changed after the soil near the surface became wet enough due to the precipitation. In the onset of monsoon, the sen- 


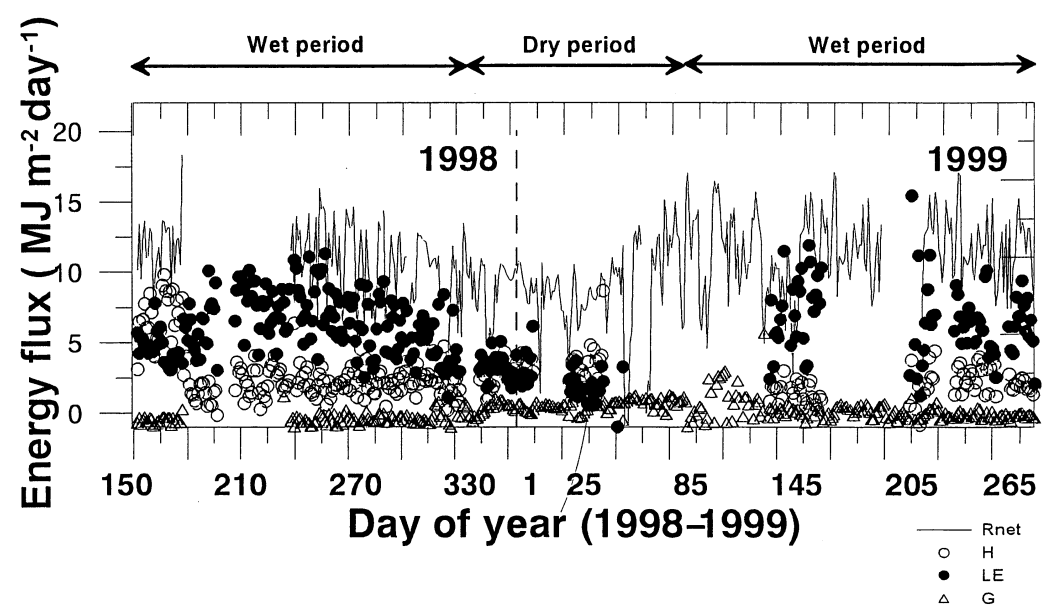

Fig. 7. Seasonal variations of the surface energy fluxes; net radiation $\left(R_{n e t} ;-\right)$, sensible heat $(H ; \bigcirc)$, latent heat $(L E ; \mathbf{O})$ and ground heat $(G ; \triangle)$ throughout the observation period ((DOY 152) 1998 to (DOY 294) 1999).

sible heat held the value $2.5 \mathrm{MJ} \mathrm{m}^{-2}$ day $^{-1}$ approximately. In contrast, the maximum of latent heat flux reached $11.11 \mathrm{MJ} \mathrm{m}{ }^{-2}$ day $^{-1}$ on 5 September (DOY 248) 1998, and $11.56 \mathrm{MJ}$ $\mathrm{m}^{-2}$ day $^{-1}$ on 28 June (DOY 179) 1999 during rainy season, and they corresponded with 5.36 $\mathrm{mm}$ day $^{-1}$ and $5.58 \mathrm{~mm}$ day $^{-1}$ for daily evapotranspiration, respectively. The ratio of latent heat flux to available energy (net radiation minus ground heat flux) was 0.96 in August 1998. Latent heat flux became equivalent to sensible heat at the end of January 1999, and re-increased in latent heat flux and re-decreased in sensible heat flux appeared in April 1999, corresponding with the decrease of surface temperature, and the increase of specific humidity as shown in Fig. 5 (c) and (e), as the onset of monsoon progressed again.

\subsection{Energy balance}

For the purpose of testing the energy balance, the conformity between the sum of the turbulent fluxes, plus ground heat flux (TFG) and the net radiation is examined in terms of two remarkably different seasons, that is, wet and dry seasons as shown in Fig. 8 (a). For this testing, 113 sets of data for wet season and 51 for the dry season without rainfall, and were selected on daily-integrated fluxes. This data selection also includes the attention of acceptable wind direction data that have no influences of wind distortion, due to the tower and sonic anemometer-thermometer. The ratios of TFG to net radiation were 0.73 (for wet season) and 0.79 (for the dry season), respectively, and the mean and standard deviations were $37.34 \mathrm{~W} \mathrm{~m}^{-2}$, and $32.01 \mathrm{~W} \mathrm{~m}^{-2}$ during the rainy season, and $25.71 \mathrm{~W} \mathrm{~m}^{-2}$, and $19.44 \mathrm{~W} \mathrm{~m}^{-2}$ during the dry season, respectively. Differences between TFG and the net radiation exceeding $50 \mathrm{~W} \mathrm{~m}^{-2}$ were found to some extent during the wet season when the latent heat flux was dominant over the other components. Also, Figs. 8 (b) and (c) show for the diurnal and nocturnal relationships between TFG and the net radiation. The use was made of data calculated by averaging with data observed during 9:00 to 5:00 Thailand Standard Time (TST) for diurnal relationship and during 0:00 to $6: 00$ and 20:00 to $24: 00$ for nocturnal relationship. The data was eliminated when the sunrise or sunset came, because there was the seasonal difference in their occurrence. The result in Fig. 8(b) indicates that there was not a remarkable difference compared to the results obtained from all data used in Fig. 8 (a). However, Fig. 8(c) shows that many data points were scattered in comparison with those for the diurnal relationship.

The unclosure of energy balance is often called the energy imbalance (Panin et al. 1998). A number of causes of imbalance have been reported at many experimental sites (e.g., Baldoc- 
(a)

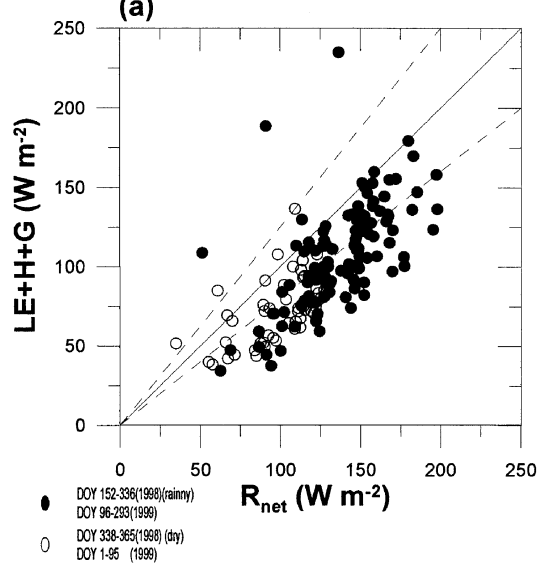

(b)

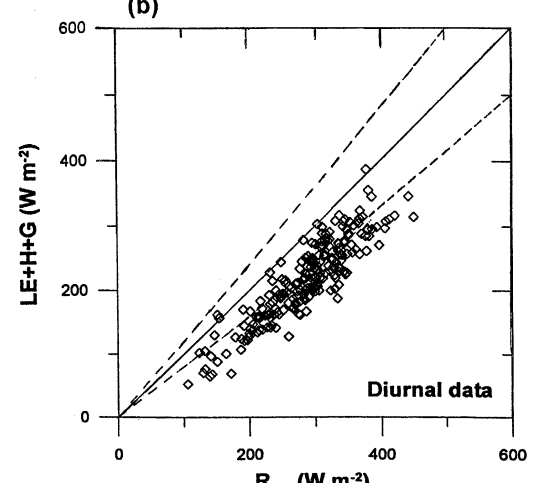

(c)

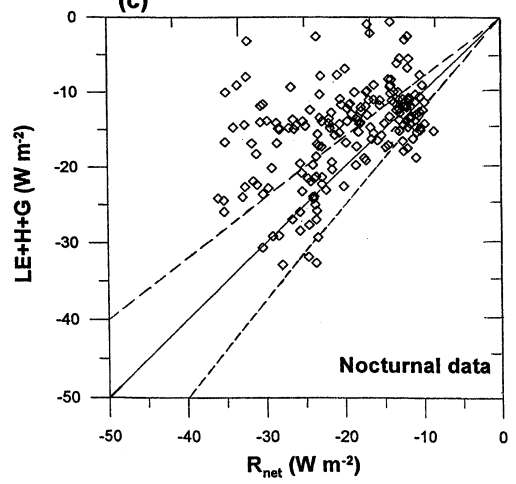

Fig. 8. Energy balance throughout the observation period ((DOY 152) 1998 to (DOY 294) 1999). (a) The relationship between sensible heat, latent heat plus ground heat flux $(H+L E+G)$ and net radiation $R_{\text {net }}$ classified for every characteristic season. Open circles indicate the dry season (December 1998 to April 1999), while closed circles indicate the wet season (June to December 1998 and April to October 1999). (b) Same as Fig. 8 (a), but applicable data in the daytime was used throughout the observation period. (c) Same as Fig. 8 (a), but applicable nocturnal data was used throughout the observation period. chi and Rao 1995; Tsukamoto et al. 1995; Twine et al. 2000; Tanaka et al. 2001). Lee (1998) discussed that a weak vertical velocity could bring about the imbalance. Additional examples (a) to (c) review some possible causes of the energy imbalance, except for the uncertainties in the measurement accuracy.

(a) The development of horizontal energy advections in association with the surface inhomogeneity (e.g., Baldocchi and Rao 1995): Baldocchi and Rao (1995) discussed the relationships between the underestimation of turbulent fluxes and terrain inhomogeneity, and showed that the underestimation of the fluxes might be due to the horizontal advection which results from spatial interaction processes between different surfaces.

(b) Breakdown of the atmospheric stationary in association with sampling and averaging time in the process of obtaining turbulent statistics (e.g., Marht 1998): Panin et al. (1998) stated that it is significant to estimate the low frequency part of the covariance spectrum associating with turbulent fluxes, in which most energy is contained, and that an appropriate sampling or an averaging time scale should be determined to accurately estimate the low frequency part of the energy spectrum, considering the mesoscale phenomena as the local circulation.

(c) Methodology for mounting instruments: It is suggested that the differences of measured height for each flux component might cause the energy imbalance. As described later in section 4.1, the upwind distance within which the measured turbulent fluxes was reflected, depends on the atmospheric stability and aerodynamic roughness, and could be extended approximately until 4000 m under neutral stability in our study site. The spatial difference in the distributions of net radiation as well as the spatial differences in surface temperature, might be due to the heterogeneous soil moisture condition. The heterogeneity of soil moisture distribution might affect the estimate of the ground heat flux.

One of the possible reasons in our study is that the measured turbulent fluxes for the present study have been underestimated in com- 


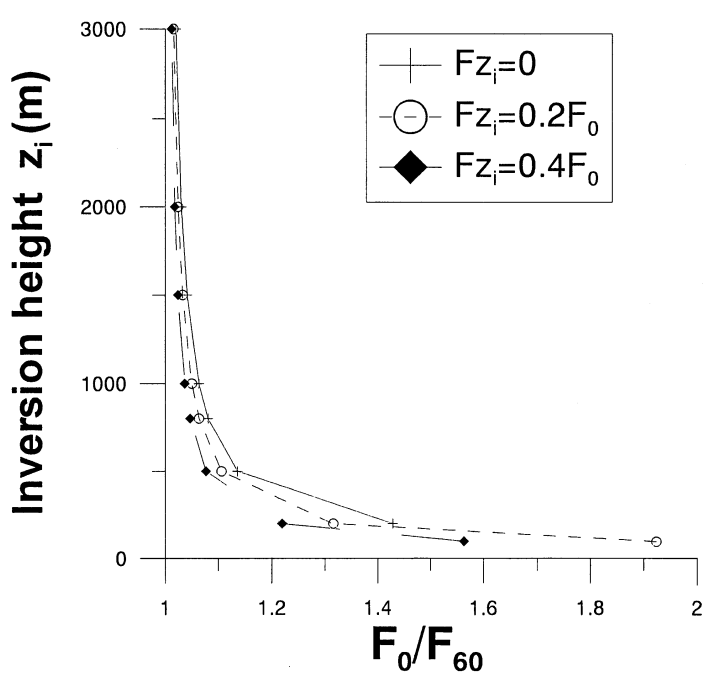

Fig. 9. Ratio of "real" surface flux $F_{0}$, to surface flux $F_{z}$, obtained at $60 \mathrm{~m}$ height $\left(F_{60}\right)$ for varying inversion height $z_{i}$, for three values of the ratio of the flux $F_{z i}$ at the inversion height to the surface flux $A$, i.e., $A=0(+), 0.2$ (line with $\bigcirc$ ) and 0.4 (line with $\diamond$ ).

parison with the "real " surface fluxes, because the measured fluxes were obtained at a height of $60 \mathrm{~m}$. Generally, sensible and latent heat fluxes decrease as the height from the surface increases (e.g., Caughy and Palmer 1979).

Assuming that the flux at ground $F_{0}$ decreases linearly with increase of height, until the upper limit of mixed layer $z_{i}$, the relation of $F_{0}$ to the flux $F_{z}$, measured at height $z$ can be written as,

$$
F_{0}=\frac{z_{i}}{z_{i}-(1-A) z} F_{z} .
$$

$z_{i}$ also indicates the inversion height. $A$ represents the ratio between $F_{0}$ and the flux $F_{z i}$ at $z_{i}$. Considering the flux $F_{z i}$ as the sensible heat flux, the value of $A$ is found to be ranging from 0 to 0.5 (e.g., Driedonks 1982; Culf 1991). Figure 9 plots the ratio of $F_{0}$ to $F_{z}$ at $60 \mathrm{~m}$ height $\left(F_{60}\right)$ with varying $z_{i}$, for three values of $A$, i.e., $A=0,0.2$ and 0.4 . The figure indicates that the ratio approaches 1 , and is not sensitive to the value of $A$ as the value of $z_{i}$ increases. In the case of $z_{i}=1000 \mathrm{~m}, F_{60}$ is $3-6 \%$ less in magnitude than $F_{0}$, and $F_{60}$ is only $1-2 \%$ underestimated, compared with $F_{0}$ at $z_{i}=3000 \mathrm{~m}$. In tropic region, the magnitude of $z_{i}$ ranges from approximately $1000 \mathrm{~m}$ to $3000 \mathrm{~m}$ in the daytime. This suggests that the value of flux obtained in the present study can almost be regarded as the surface flux in the daytime, but as an underestimate by less than $6 \%$ of the flux at the ground.

Another reason is that the validity of the latent heat flux calculation using bandpass technique might have not obtained the sufficiently with high accuracy. The small value of $b\left(=[2 \pi \mu]^{2} \beta\right)$ recorded using PAM III as stated in Section 2.3, is the indication of the scatter of the cospectra data set, and the scatter causes when the magnitude of flux is very small under stable conditions, In the current improved algorithm of PAM III, the higher $b$ value should be obtained because of the expansion of the bandwidth (Horst et al. 1997). In our case, a wider range of $b$ value was obtained in the range from 0 to 64 including daytime and nighttime during the observation period, and most of $b$ were concentrated between 30 to 50 . The results support that reliable latent heat flux using the bandpass technique could be obtained with sufficient cospectral similarity between $w^{\prime} t^{\prime}$ and $w^{\prime} q^{\prime}$. The number of data between $b=30$ to 50 reached $80 \%$ of all the data. However, data with small $b$ value was occasionally seen even when large sensible heat flux was measured under unstable stratification. More improvements might be needed for determining the latent heat flux using the PAM III.

Even if these should be considered as the reasons of imbalance, however, the energy imbalance is still unresolved. At any rate, approximately 70 to $80 \%$ of energy closure obtained on a daily-integrated basis was similar to that of many other flux measurement fields.

\subsection{Diurnal variation of surface energy fluxes}

The typical diurnal variations of the surface fluxes are represented for dry and rainy season in Figs. 10 (a)-(d), with the difference in soil moisture conditions. Data herein were obtained on clear days in the absence of temporal rainfall, except for Fig. 10 (c). The predominant sensible heat flux surpassed latent heat flux on June 19 (DOY 200) 1998 (Fig. 10 (a)). During this period, the influence of the monsoon rain on the surface fluxes was still slight, since recharge of the soil moisture due to rainfall was not sufficient, because of the dry condition for soil sur- 

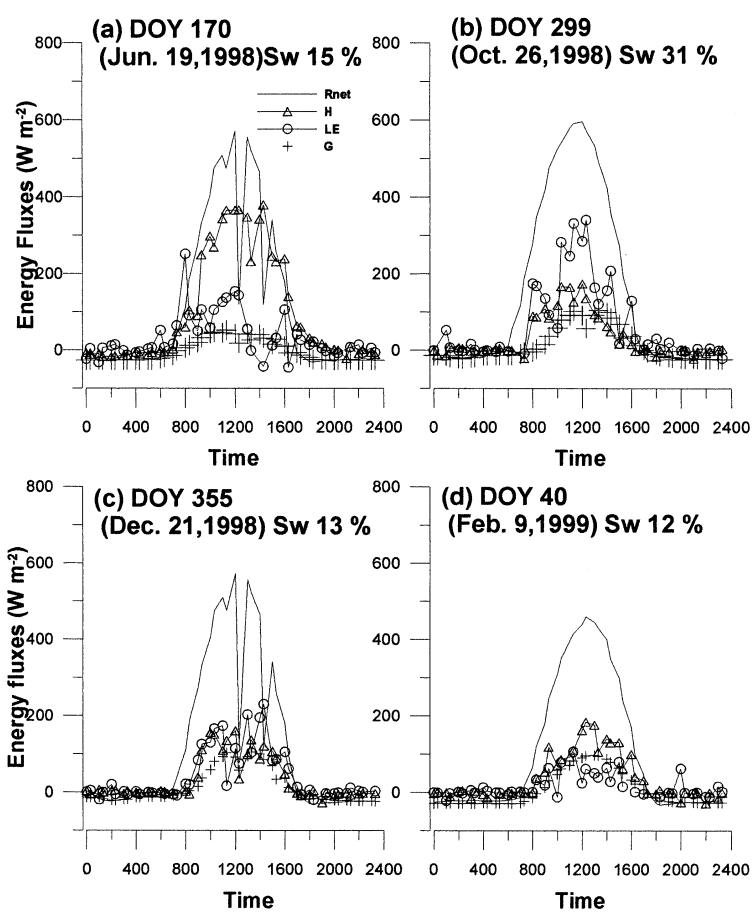

Fig. 10. Diurnal variations of the surface energy fluxes; net radiation $\left(R_{n e t} ;-\right)$, sensible heat $(H ; \triangle)$, latent heat $(L E$; $\bigcirc)$ and ground heat $(G$; +) on (a) 19 June 1998, (b) 26 October 1998, (c) 21 December 1998, and (d) 9 February 1999 with the value of volumetric water content $\left(S_{w}\right)$. The notation of time is specified as Thailand Standard Time (TST).

face during the previous dry season. The value of sensible heat flux reached approximately $400 \mathrm{~W} \mathrm{~m}^{-2}$ in June 1998.

Both of Figs. 10 (a) and (c) show the transitional periods from the dry to wet season and from the wet to dry, respectively. The maximum sensible heat flux was approximately $200 \mathrm{~W} \mathrm{~m}^{-2}$ during December 1998 in Fig. 10 (c), and was much smaller than that of the dry-wet period in Fig. 10 (a). Evaporative fractions, which are defined as the quotient of the latent heat flux to the summation of the sensible and latent heat fluxes, were 0.62 on daily average for Fig. 10 (a), and 0.56 for Fig. 10 (c).

Figure 10 (b) shows the diurnal variation of the energy balance on 26 October (DOY 299) in 1998 for the rainy season, and Fig. 10 (d) is 9 February (DOY 40) 1999 for the dry season. La-

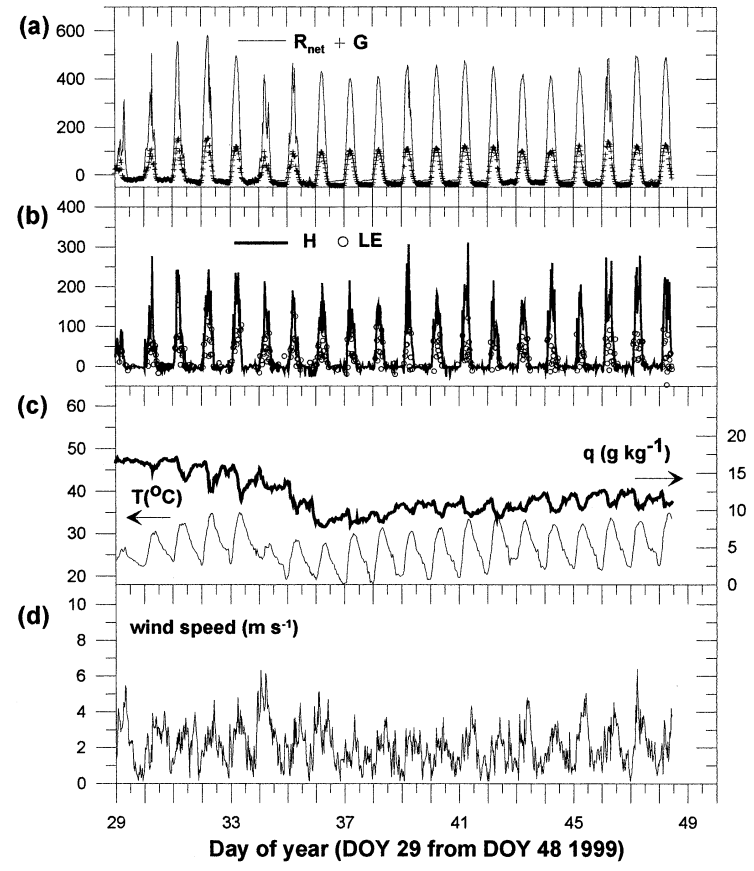

Fig. 11. Diurnal variations of meteorological and variables during the dry season from (DOY 29) to (DOY 48) 1999. (a) net radiation $\left(R_{n e t} ;-\right)$ and ground heat flux $(G ;+)$, (b) sensible heat flux $(H ;-)$ and latent heat flux $(L E ; O),(c)$ air temperature $(T)$ and specific humidity $(q),(\mathrm{d})$ wind speed at $30 \mathrm{~m}$ height.

tent heat flux was predominant when the soil contained sufficient moisture, after the onset of the monsoon with frequent events in rainfall. As shown in Fig. 10 (b), the hourly maximum of latent heat flux was $360 \mathrm{~W} \mathrm{~m}^{-2}$ in daytime. The magnitude of sensible heat flux had its maximum value of about $185 \mathrm{~W} \mathrm{~m}^{-2}$ at 12:00 TST, about a half of latent heat flux. In contrast, for the dry period in Fig. 10 (d), the maximum latent heat flux was $100 \mathrm{~W} \mathrm{~m}^{-2}$ at daily maximum, with gradual decrease toward the evening, and turned negative at 17:00 TST. Figures 11 (a) to (d) show the variations for the surface fluxes, and the meteorological variables during the dry season from 29 January (DOY 29) to 16 February (DOY 47) 1999. The result in Fig. 11 (b) indicates the values of latent heat flux in daytime reached $150 \mathrm{~W} \mathrm{~m}^{-2}$ at daily maximum through this period, corresponding with the variation of specific humidity in Fig. 11 (c). In chapter 4 , the discussions are made 
for the evaporative sources that contributed to the measured latent heat flux during the dry season.

\section{Discussion}

\subsection{Evaporative source area of the latent heat flux over the complex terrain in the dry season}

It is significant to evaluate where and how the source area of the latent heat flux exists over a complex terrain during the dry season. Thus, the upwind source area should be evaluated to determine the representativeness of the flux measurement. One of the calculation methods is known as footprint analysis (Schuepp et al. 1990; Horst and Weil 1994). Details in footprint analysis calculation in the present study are summarized in Appendix A.

Horst and Weil (1994) (HW94) discussed how far is far enough to require the fetch, which indicates the upwind distance from the tower, reflecting the surface fluxes for flux measurement within a fraction of the surface flux error. They concluded that fetches one hundred times longer than the measurement height should be required for the measured flux to contain the accuracy within $10 \%$ to $20 \%$ of the surface fluxes. In other words, the surface flux measured at a higher height can represent the surrounding land cover on an extended spatial scale. However, it does not appear to be enough just to multiply solely the measurement height by one hundred, because of the dependency of the effective fetch on the atmospheric stability and surface roughness.

As shown in Fig. 12, data from the dry season 1999 as shown in Fig. 12 is used for this footprint analysis. In the process of calculation, data is selected in the following criteria. (I) Wind direction $W D$ should be in the range of $20^{\circ}<W D<120^{\circ}$ or $240^{\circ}<W D<300^{\circ}$. This reflects the wind distortion due to the tower structure, and sonic anemometer itself. (II) When momentum flux is greater than -0.02 $\mathrm{m} \mathrm{s}^{-1}$, it is rejected. (III) When the value of the latent heat flux is smaller than $10 \mathrm{~W} \mathrm{~m}^{-2}$, with data which the atmospheric stationary is held stable, it is rejected. Figure 12 shows the relative source strength upwind from the observation tower for the roughness length for momentum $z_{0}=0.4 \mathrm{~m}$, which was derived by finding the $z_{0}$ value that gives the minimum root mean



Fig. 12. Relationship of relative source strength to distance upwind for two levels of stability condition $-\left(z_{m}-d\right) /$ $L_{m}\left(-\left(z_{m}-d\right) / L_{m}=0.18\right.$ for neutral, and $-\left(z_{m}-d\right) / L_{m}=4.26$ for unstable condition) during the dry season, 1999.

square error between friction velocities obtained from eddy correlation method and from the profile method equation based on the MoninObukhov similarity theory (Toda and Sugita 2002). Also shown is the result for two levels of the neutral (11 February, (DOY 42) 1999), and unstable conditions (4 February, (DOY 35) 1999). Close to a neutral stability condition ( $y=$ $\left.-\left(z_{m}-d\right) / L_{m}=0.18\right)$, most of the flux contributions lay through wider areas up to $4000 \mathrm{~m}$, and the peak of the footprint was approximately $400 \mathrm{~m}$ from the measurement point. It means that with smaller $y$ toward the neutral stability, the measured surface flux reflected more extended spatial scale. The result in Fig. 12 also represents that evaporative source area until $2000 \mathrm{~m}$ upwind area from the measurement point might have produced about $80 \%$ of latent heat flux. Assuming the upwind area over $2 \times 2$ square kilometers, approximately $80 \%$ of the corresponding area was occupied by a combination of evergreen and deciduous forest: each percentage of deciduous forest, evergreen forest, farmland \& grassland, bare soil, water reservoir, and paddy field is $25.9 \%$, $53.9 \%, 5.3 \%, 0.9 \%, 1.7 \%$, and $5.9 \%$ of the upwind area. In contrast, the footprint for the 
unstable condition with $y=4.26$, was smaller compared with that for the former stability condition and the most flux contribution (more than $85 \%$ ) concentrated up to approximately $500 \mathrm{~m}$, with the primal peak at $100 \mathrm{~m}$ of upwind distance. This is because the buoyancy production of turbulence is greater compared with the mechanical shear production, as the strength of unstable stability increases. From the relationships between the flux contribution obtained from the footprint analysis, and the land cover distribution, it was presumed largely that there might exist the evaporative release from the forest observed during the dry season. Indeed, Toda et al. (2000b) shows that downward carbon dioxide flux from the atmosphere to the surface was observed in daytime from the intensive carbon dioxide flux observations conducted over the corresponding site during the dry season in 1998 and 1999. The result supports the terrestrial land covers, particularly forest area around the tower, can be considered as the evaporative source together with the carbon sink. However, the results for the preceding footprint analysis and Toda et al. (2000b) might not necessarily allow the forests around the tower to work as the dominant evaporative source, because other land covers have the possibility to behave as evaporative source, such as water reservoirs, paddy field and soil evaporation. Thus, details in each evaporative source are discussed in the following.

A simple test was given for estimating possible evaporation from a water reservoir around the tower by means of the bulk method.

The bulk transfer coefficient for latent heat $C_{E}$ can be written in the following form,

$$
C_{E}=k^{2} /\left[\ln \left(z_{m} / z_{w 0}\right) \cdot \ln \left(z_{m} / z_{w q}\right)\right],
$$

where $z_{w q}$ is roughness length for latent heat over a water surface, and $k$ is the von Karman constant $(k=0.4)$. Kondo (1994) summarized a set of $z_{w 0}$ and $z_{w q}$ over a water surface for the condition of wind speed $U_{10}$ at $10 \mathrm{~m}$ height; the values of $z_{w 0}$ and $z_{w q}$ under $U_{10}=2 \mathrm{~ms}^{-1}$ were $0.27 \times 10^{-4}$, and $1.23 \times 10^{-4}$. The bulk transfer coefficient for latent heat $C_{E}$ was obtained as $1.77 \times 10^{-4}$, under $U_{10}=2 \mathrm{~ms}^{-1}$. Evaporation from water reservoir $E_{D}$, with the bulk method is given by,

$$
E_{D}=C_{E} \rho\left(q_{w s}-q_{w}\right) U_{10}
$$

Table 2. Comparison between the evapotranspiration $E_{\text {all }}$ obtained using the bandpass technique and the evaporation from water reservoir $E_{D}$ under wind speed $U_{10}$ at $10 \mathrm{~m}$ height; $U_{10}=2 \mathrm{~ms}^{-1}$ with the bulk method with three selected data for 2 days during the dry season (23 February (DOY 54) and 3 March (DOY 62) 1999). The value of $E_{D}$ is multiplied by the area ratio of water reservoir to the upwind area over $2 \times 2$ square kilometers around the observation tower.

\begin{tabular}{ccccccc}
\hline DAY & TIME & $\begin{array}{c}\mathrm{q}_{\mathrm{s}} \\
(\mathrm{g} / \mathrm{kg})\end{array}$ & $\begin{array}{c}\mathrm{q} \\
(\mathrm{g} / \mathrm{kg})\end{array}$ & $\begin{array}{c}\mathrm{E}_{\text {all }}\left(\times 10^{-5}\right) \\
\left(\mathrm{mms}^{-1}\right)\end{array}$ & $\begin{array}{c}\mathrm{E}_{\mathrm{D}}\left(\times 10^{-5}\right) \\
\left(\mathrm{mms}^{-1}\right), \mathrm{U}_{10}=2 \mathrm{~ms}^{-1}\end{array}$ & $\mathrm{E}_{\mathrm{D}} / \mathrm{E}_{\text {all }}$ \\
\hline 19990223 & 900 & 19.4 & 14.3 & 2.57 & 1.33 & 52.0 \\
19990303 & 857 & 22.0 & 13.6 & 4.6 & 2.17 & 47.3 \\
19990303 & 1034 & 27.6 & 12.5 & 4.49 & 3.91 & 87.1
\end{tabular}

where saturated specific humidity $q_{w s}$ was calculated using the water temperature measured in one of the water reservoirs about $500 \mathrm{~m}$ south of the tower, and the specific humidity $q_{w}$ was calculated using dry and wet temperature measured over the water surface.

The values of evapotranspiration $E_{\text {all }}$ measured using the bandpass technique and that of evaporation from water reservoir $E_{D}$ under $U_{10}=2 \mathrm{~ms}^{-1}$, with the bulk method using equations (15) and (16) are compared with selected three data for 2 days during the dry season (23 February and 3 March) 1999. Note that $E_{D}$ is multiplied by the area ratio of water reservoir to the upwind area over $2 \times 2$ square kilometers around the observation tower. Data are selected when the sufficient value of $b$, for the latent heat flux calculation by means of bandpass technique as stated in section 2.3 can be obtained.

Table 2 shows that $E_{D}$ for all data was approximately more than $50 \%$ of the value of $E_{\text {all }}$ under $U_{10}=2 \mathrm{~ms}^{-1}$, reflecting the large difference between $q_{w s}$ and $q_{w}$. The result indicates that the contribution of water reservoir to the latent heat flux obtained by the tower measurement was dominant in the daytime, in comparison with the evaporative contribution from the other surfaces.

During this period in the absence of the rainfall, paddy was not cultivated because there was no irrigation system around the site, and most of the grassland left blasted. The $L A I$ of 
the paddy and grassland were very small from the relationship between the land cover map, and the inspection from photographs as shown in Fig. 2. Toda et al. (2000b) shows the results using observation data obtained over a paddy field about $30 \mathrm{~km}$ from the present site during the dry season in 1998; the data shows that there was no evaporation from the paddy field, although the scattered forest around the paddy field acted as a source of evaporation. Therefore, the evaporation from the paddy field can be ignored during the dry season.

Soil evaporation should be investigated as the third evaporative source. Unfortunately, sufficient data to describe the estimate of the soil evaporation qualitatively was not obtained during the corresponding period, because the sensors used in this study failed to extract the small change of the soil water content. However, the evaporation from the soil can be ignored in comparison with that from water reservoirs. Hence, the above examinations support that the evaporation from the water reservoirs might have relatively contributed to the value of measured latent flux compared with that from other possible sources during the dry season, although the fraction of the water reservoirs was smaller than the forest within the upwind area.

\subsection{Annual estimations of energy components and evapotranspiration}

As described in chapter 1 , the important aim of this study is to estimate the annual energy balance and evapotranspiration. However, observation could not be made for a whole year owing to failures of the instruments problems, and the systematic difficulties for data acquisition. The total energy balance and evapotranspiration were calculated during June 1998 to February 1999 in which the turbulence fluxes were measured sufficiently, and both dry and wet period were included during these nine months. The 5-day mean data was computed for all of the components with data obtained for 222 of the 303 days of this period.

Monthly average values of daily integrated energy balance components, and evapotranspiration, are shown in Table 3. Annual observation results show the turbulent fluxes varied remarkably in response to the meteorological changes that characterize the tropical monsoon climate. As shown in Table 3, the energy closure $\Delta=\left(R_{n e t}-L E-H-G\right)$ was greater during the wet season, when latent heat is the predominant energy flux, and the result corresponded with that of Tanaka et al. (2001). As indicated in Table 3, evapotranspiration in the averaged dry and wet season were 1.14 and $2.33 \mathrm{~mm}$ day $^{-1}$, respectively. Figure 13 shows the cumulative evapotranspiration and precipitation during the nine-month period. The sum of the evapotranspiration reached $526 \mathrm{~mm}$, while the total precipitation was $641 \mathrm{~mm}$. This indicates that more than 80 percentage of precipitation replaced by the evapotranspiration loss.

Table 3. Monthly estimations of the surface energy flux components and evapotranspiration on a daily integrated basis from July 1998 to February 1999. $\Delta$ represents the residual of energy balance closure.

\begin{tabular}{|c|cccccc}
\hline Month & $\mathrm{R}_{\mathrm{NET}}(\mathrm{MJ})$ & $\mathrm{G}(\mathrm{MJ})$ & $\mathrm{H}(\mathrm{MJ})$ & $\mathrm{LE}(\mathrm{MJ})$ & $\Delta$ & $\mathrm{E}_{\left(\mathrm{mm}_{\text {day }}{ }^{-1}\right)}$ \\
\hline 1998.6 & 11.91 & -0.46 & 6.25 & 4.16 & 1.95 & 1.71 \\
7 & - & - & 1.60 & 6.63 & - & 2.72 \\
8 & 12.82 & -0.35 & 1.67 & 8.01 & 3.49 & 3.29 \\
9 & 11.77 & -0.47 & 1.53 & 7.08 & 3.63 & 2.90 \\
10 & 10.07 & -0.45 & 1.91 & 5.60 & 3.02 & 2.30 \\
11 & 10.09 & -0.16 & 1.75 & 4.25 & 4.26 & 1.75 \\
12 & 9.19 & 0.37 & 3.02 & 2.64 & 3.16 & 1.08 \\
1999.1 & 8.12 & 0.38 & 3.13 & 2.84 & 1.77 & 1.16 \\
2 & 8.72 & 0.46 & 3.28 & 1.53 & 3.44 & 0.63 \\
\hline
\end{tabular}




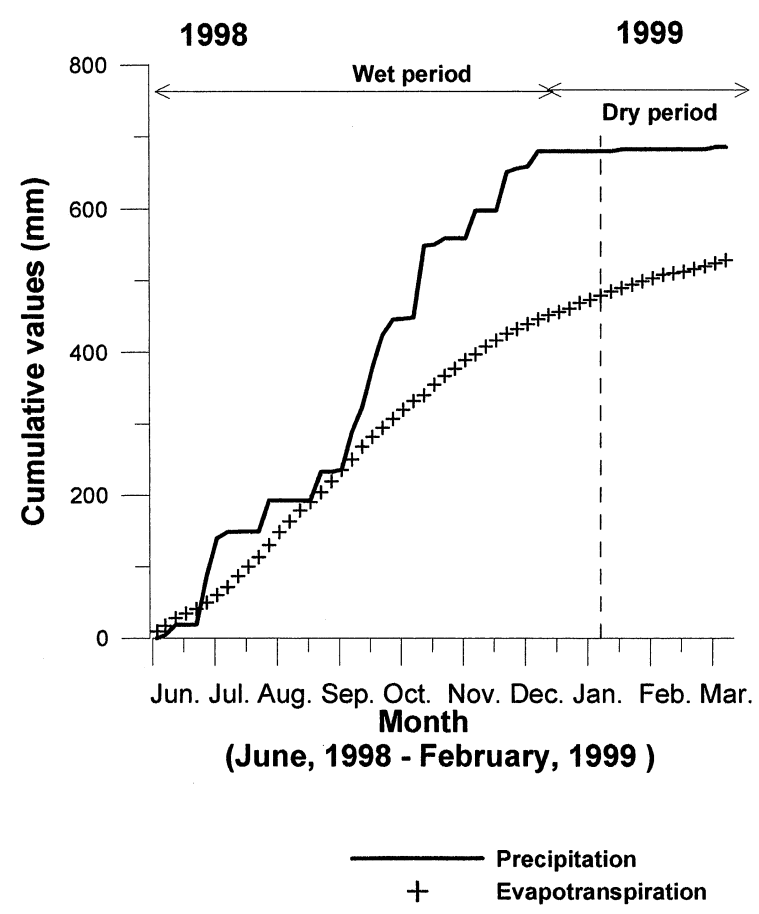

Fig. 13. Cumulative values for precipitation and evapotranspiration throughout the observation period from June 1998 to February 1999. Plus sign denotes the amount of evapotranspiration, and solid line indicates the amount of precipitation.

Some estimations of the annual evapotranspiration have been done at experimental sites surrounded by a tropical environment in low latitudes using various evaluation techniques such as satellite data (e.g., Kondoh 1995), and large river basin data (e.g., Oki 1993). They showed some cases in which the amount of precipitation replaced completely by the sum of evaporation due to the combination of transpiration of the vegetation activities and evaporation from the soil. The results of our experiment corresponded approximately to the previous study by Hirota (2001) which examined total evapotranspiration over bare soil and lawn area in Thailand using the routine meteorological data at Bankok and Chiang Mai in the Chao Phraya river basin in Thailand by the heat balance model method and Force-Restore method, and found that the value of evapotranspiration reached $760 \mathrm{~mm}$ to the total precipitation of $1000 \mathrm{~mm}$. Furthermore, evapotranspiration was estimated during the dry season in the absence of rainfall. From 7 December (DOY 341) 1998 to 28 February (DOY 60) 1999 of the studied period, the total evapotranspiration for these 84 days reached 76.5 $\mathrm{mm}$, while precipitation was only $5.5 \mathrm{~mm}$.

\section{Conclusion}

This study evaluated seasonal variation of heat and water vapor exchanges between the atmosphere and terrestrial land surfaces observed in a tropical monsoon environment. A seasonal difference in surface fluxes between wet and dry seasons was seen, and the latent heat flux was dominant in the monsoon, corresponding with the increase of specific humidity after frequent precipitation. The sensible heat flux increased as the surface temperature increased in the absence of rainfall during the dry season.

During the observation period from July 1998 to February 1999, the average values of net radiation, sensible heat, latent heat and ground heat flux were estimated on a daily integrated basis, and both sensible and latent heat fluxes were the predominant energy partitioning components throughout the year. However, the energy balance remains unresolved as with the previous experimental studies, although several possibilities for resolving this problem were considered. One of the new findings is that the estimated amount of evapotranspiration reached $526 \mathrm{~mm}$ versus $641 \mathrm{~mm}$ of actual precipitation, accounting for about $80 \%$ of the actual precipitation during this period.

Toda et al. (2000b) shows that the daytime carbon dioxide was transferred from atmosphere to the terrestrial surfaces during the rainy and dry seasons in 1998 and 1999. The results indicate that the terrestrial land covers, particularly forest area around the tower can be considered as the evaporative source together with the carbon sink through the entire period. From the examinations to identify sources of evaporation during dry season, which contributed to the latent heat flux obtained from tower measurements over complex land covers, it was concluded that the evaporative contribution of the water reservoirs around the tower relatively dominated compared with that of the forests. Inhomogeneity in the land surface appears to make it complex to evaluate the be- 
havior of surface fluxes. In order to quantify the evaporative release related with terrestrial response, further experimental studies are needed to enhance the understanding of the plant response from leaf to regional canopy scale.

\section{Acknowledgements}

This work has been conducted as part of the GAME campaign, which was supported by a grant-in-aid for the Scientific Research on Priority Area (B) (2) from the Fund of the Japanese Ministry of Education and Culture for Science Research (11201202). This study also received supplementary funding from the ASAHI Beer Academic Promoted Foundation. The authors express their deep appreciation to T. Watanabe and T. Hirota for their valuable and encouraging advice and suggestions. They would also like to acknowledge helpful advices from I. Tamagawa, M. Sugita, T. Hiyama, and A. Numaguchi. Finally, we would like to express our gratitude to J. Matsumoto and his colleagues for their additional helpful comments. Special thanks are dedicated to P. Polsan and C. Wichai of his staff of the Royal Irrigation Department in Thailand, and S. Miyazaki for their great contributions to the fieldwork.

\section{Appendix A}

\section{Footprint calculation}

The footprint analysis on the basis of Schuepp et al. (1990) was made to enhance our knowledge on how each contribution for the surface flux from the ground has diffused. The model modified to include the stability effect is

$$
\begin{aligned}
\frac{1}{Q_{0}} \frac{d Q}{d x} & =\frac{U\left(z_{m}-d\right)}{u_{*} k x^{2}} \phi_{h} \exp \left(-\frac{U\left(z_{m}-d\right)}{k u_{*} x} \phi_{h}\right) \\
& =\frac{2 x_{\max }}{x^{2}} \phi_{h} \exp \left(\frac{-2 x_{\max }}{x} \phi_{h}\right), \quad(\mathrm{A}-1)
\end{aligned}
$$

where $Q_{0}$ represents the relative source strength per unit area flux density, and $x$ is the upwind distance from the flux measurement. $u_{*}$ the friction velocity, and $U$ the constant wind velocity, and $\phi_{h}=[1-16 y]^{-0.5} \cdot x_{\max }$ represents the position of the peak of the footprint as

$$
x_{\max }=\frac{U}{u_{*}} \frac{\left(z_{m}-d\right)}{2 k} .
$$

Rewriting equation (A-2) with only parameters of stability length, and aerodynamic roughness (Lloyd 1995), $x_{\max }$ is rewritten as

$$
x_{\max }=1.7 z_{m}^{1.03} \frac{\left[\ln z_{m} / z_{0}-\Psi_{h}(y)\right]}{1+y} .
$$

Where $\Psi_{h}$ means the stability correction function for sensible and latent heat. The form was used of the function for $\Psi_{h}$ of Brutsaert (1992) obtained using both of the proposals of Kader and Yaglöm (1990), and the analysis of Högström (1988) for the atmospheric conditions, since the result of Sugita et al. (1995) showed that Brutsaert's function was applicable under strong unstable stability conditions. The general form of $\Psi_{h}$ can be written as

$$
\Psi_{h}(y)=1.20 \ln \left[\left(0.33+y^{0.78}\right) / 0.33\right] .
$$

\section{References}

Aoki, M., T. Chimura, K. Ishii, I. Kaihotsu, T. Kurauchi, K. Mushiake, T. Nakaegawa, N. Ohte, P. Polsan, S. Semmer, M. Sugita, K. Tanaka, O. Tsukamoto, and T. Yasunari, 1998: Evaluation of surface fluxes over a paddy field in tropical environment: Some findings from a preliminary observation of GAME, J. Jpn. Soc. Hydrol. \& Water Resour., 11, 39-60.

Baldocchi, D.D. and K.S. Rao, 1995: Intra-field variability of scalar flux densities across a transition between a desert and an irrigated potato field, Boundary-Layer Meteor., 76, 109-136.

Black, T.A., G. Den Hardtop, H.H. Neumann, P.D. Blanken, P.C. Yang, C. Russell, Z. Nesic, X. Lee, S.G. Chen, R. Staebler, and M.D. Novak, 1996: Annual cycles of water vapour and carbon dioxide fluxes in and above a boreal aspen forest, Global Change Biology, 2, 219-229.

Brutsaert, W., 1992: Stability Correction Functions in the Mean Wind Speed and Temperature in the unstable Surface Layer, Geophys. Res. Lett., 19, 469-472.

Caughy, S.J. and S.G. Palmer, 1979: Some aspects of turbulence structure through the depth of the convective boundary layer, Quart. J. Roy. Meteor. Soc., 105, 811-827.

Culf, A.D., 1991: An application of simple models to Sahelian convective boundary-layer growth, Boundary-Layer Meteor., 58, 1-18.

Driedonks, A.G.M., 1982: Models and observations of the growth of the atmospheric boundary layer, Boundary-Layer Meteor., 23, 283-306.

Greco, S. and D.D. Baldocchi, 1996: Seasonal variations of $\mathrm{CO}_{2}$ and water vapour exchange rates 
over a temperate deciduous forest, Global Change Biology, 2, 183-197.

Hicks, B.B. and R.T. McMillen, 1988: On the measurement of dry deposition using imperfect sensors and in non-ideal terrain, BoundaryLayer Meteor., 42, 79-94.

Hirota, T., 2001: An estimation of seasonal and annual actual evaporation using agrometeorological data of Thai meteorological department by the force-Restore Model, J. Meteor. Soc. Japan, 79, 365-371.

Horst, T.W. and J.C. Weil, 1994: How far is far enough?: The fetch requirements for micrometeorological measurement of surface fluxes, J. Atmos. Ocean. Tech., 11, 1018-1025.

- and S.P. Oncley, 1995: Flux-PAM measurement of scalar fluxes using cospectral similarity, Ninth AMS Symposium on Meteorological Observations and Instrumentation, Charlotte, NC, March 1995.

- S.P. Oncley, and S.R. Semmer, 1997: Measurement of water vapor fluxes using capacitance $\mathrm{RH}$ sensors and cospectral similarity, 12th AMS Symposium on Boundary Layers and Turbulence, Vancouver, BC, Canada.

Högström, U., 1988: Non-dimensional wind and temperature profiles in the atmospheric surface layer, Boundary-Layer Meteor., 42, 5578.

Kabat, P., A.J. Dolman, and J.A. Elbers, 1997: Evaporation, sensible heat and canopy conductance of fallow savannah and patterned woodland in the Sahel, J. Hydorology, 188-189, 494-515.

Kader, B.A. and A.M. Yaglom, 1990: Mean fields and fluctuation moments in unstably stratified turbulent boundary layers, J. Fluid Mech., 211, 637-662.

Kondo, J., ed., 1994: Meteorology of the water environment. - Water and heat balance of the earth-ASAKURA Co. Ltd., 337pp. (in Japanese).

Kondoh, A., 1995: Changes in Evapotranspiration due to Anthropogenic Changes in land Cover in Monsoon Asia. J. Jpn. Soc. Photogrammetry and remote Sensing, 34, 4, 13-21.

Lee, X., 1998: On micrometeorological observations of surface-air exchange over tall vegetation, Agric. For. Meteor., 91, 39-49.

Lloyd, C.R., 1995: The effect of heterogeneous terrain on micrometeorological flux measurements: a case study from HAPEX-SAHEL, Agric. For. Meteor., 73, 209-216.

Matsumoto, J., 1997: Seasonal transition of summer rainy season over Indochina and adjacent monsoon region, Advanes Atmos. Sci., 14, 232245.
Mahrt, L., 1998: Flux sampling errors for aircraft and towers, J. Atmos. Oceanic. Tech., 15, 416429.

Miyazaki, S., T. Yasunari, and T. Adyasuren, 1999: Abrupt Seasonal Changes of Surface Climate Observed in Northern Mongolia by an Automatic Weather Station. J. Meteor. Soc. Japan, 77, 583-593.

Nemani, R.R. and S.W. Running, 1989: Testing a theoretical climate soil leaf area hydrologic equilibrium of forests using satellite data and ecosystem simulation, Agric. For. Meteor., 44, 245-260.

Oki, T., 1993: Tropical rivers from the point of hydrological climatology, kagaku, 63, 678-682.

Ohtani, Y. and K. Yamanoi, 1992: Turbulent transport characteristics of momentum, sensible heat, and water vapor above a forest canopy, $J$. Jpn. For. Soc., 74, 213-220.

Panin, G.N., G. Tetzlaff, and A. Raabe, 1998: Inhomogeneity of the land surface and problems in the parameterization of surface fluxes in natural conditions, Theor. Appl. Climatol., 60, 163-178.

Rosset, M., M. Riedo, A. Grub, M. Geissmann, and J. Fuhrer, 1997: Seasonal variation in radiation and energy balances of permanent pastures at different altitudes, Agric. For. Meteor., 86, 245-258.

Schuepp, P.H., M.Y. Leclerc, J.I. Macpherson and R.L. Desjardins, 1990: Footprint prediction of scalar fluxes from analytical solutions of the diffusion equation, Boundary-Layer Meteor., 50, 355-373.

Seginer, I., P.J. Mulhearn, E.F. Bradley, and J.J. Finnigan, 1976: Turbulent flow in a model plant canopy, Boundary-Layer Meteor., 10, 423-453.

Sugita, M., T. Hiyama, N. Endo and S.-F. Thian, 1995: Flux determination over asmooth surface under strongly unstable conditions, BoundaryLayer Meteor., 73, 145-158.

Tanaka, K., H. Ishikawa, T. Hayashi, I. Tamagawa, and Y. Ma, 2001: Surface energy budget at Amdo on the Tibetan plateau using GAME/ Tibet IOP98 data, J. Meteor. Soc. Japan, 79, 505-517.

Toda, M., N. Saigusa, T. Oikawa, and F. Kimura, 2000a: Seasonal changes of the $\mathrm{CO}_{2}$ and $\mathrm{H}_{2} \mathrm{O}$ exchanges over a temperate grassland. J. Agri. Meteor., 56, 197-207. , N. Ohte, M. Tani, H. Tanaka, K. Musiake, M. Aoki, and S. Boonyamat, 2000b: Diurnal and seasonal variations of $\mathrm{CO}_{2}$ exchange processes over typical land covers in tropical monsoon region, J. Jpn. Soc. Hydorol. \& Water Resour., 13, 276-290. (In Japanese) 
and M. Sugita, 2002: Single level turbulence measurements to determine roughness parameters of complex terrain. (submitted)

Twine, T.E., W.P. Kustas, J.M. Norman, D.R. Cook, P.R. Houser, T.P. Meyers, J.H. Prueger, P.J. Starks, and M.L. Wesely, 2000: Correcting eddy-covariance flux under- estimates over a grassland, Agric. For. Meteor., 103, 279-300.

Watanabe, T., K. Yamanoi, and Y. Yasuda, 2000: Testing of the bandpass eddy covariance method for a long-term measurement of water vapour flux over a forest, Boundary-Layer $\mathrm{Me}$ teor., 96, 473-491. 